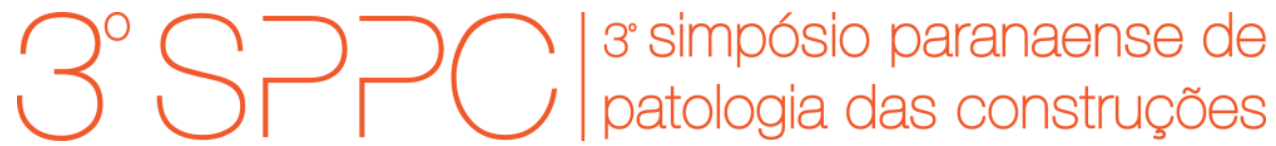

ISSN 2526-7248 artigo n. 3SPPC1013, pp. 143-155, 2018

\title{
Influência do consumo de cimento na dosagem do concreto sobre a formação da película passivadora do aço
}

\author{
Esteves, lan César Amos ${ }^{1}$; Hino-Júnior, José Roberto ${ }^{2}$; Réus, Giovana Costa ${ }^{3}$; \\ Medeiros, Marcelo Henrique Farias ${ }^{4}$ \\ ${ }^{1}$ Mestrando, Universidade Federal do Paraná, estevesian3@gmail.com \\ ${ }^{2}$ Mestrando, Universidade Federal do Paraná, jr.hinojr@outlook.com \\ ${ }^{3}$ Mestra, Universidade Federal do Paraná, gio_reus@yahoo.com.br \\ ${ }^{4}$ Professor e Doutor, Universidade Federal do Paraná, medeiros.ufpr@gmail.com
}

Resumo: Quando inseridas em meio alcalino, como o concreto, as barras de aço são protegidas da corrosão física e quimicamente através da formação de uma película passivadora. Diversos pesquisadores estudaram a formação de tal película em soluções alcalinas que simulassem 0 concreto, acelerando assim sua formação, o que não permite a análise da cinética desta reação. Tendo isto em vista, este trabalho tem como objetivo explorar o tempo e velocidade de formação da camada de passivação, através de leituras de potencial de corrosão, velocidade de corrente de corrosão e resistividade elétrica, em concretos com três diferentes consumos de cimento. Os resultados das leituras iniciadas no terceiro dia e mantidas até o $124^{\circ}$ de idade do concreto não apontaram a formação de passivação do aço, apesar da redução significativa da velocidade de corrosão até a data da última leitura. Além disso, as variações de consumo de cimento mostraram-se pouco significantes quando analisados os resultados de velocidade e potencial de corrosão.

Palavras-chave: Corrosão, Película passivadora, Potencial de corrosão, Resistividade elétrica superficial, Durabilidade.

\begin{abstract}
When inserted in alkaline medium, such as concrete, steel reinforcement bars are protected from physical and chemical corrosion by the formation of a passivation layer. Several researchers have studied the passivation development in alkaline solutions that simulate concrete, thus accelerating its formation, which compromises the analysis of this reaction kinetics. Considering that, this work aims to analyse the time and velocity of the passivating film formation, by measuring, in different ages, half-cell potential, corrosion current velocity and electrical resistivity in concretes with three different cement consumptions. The results of the readings initiated on the third day and maintained until the 124th day of the concrete did not indicate the steel passivation, despite the significant reduction of the corrosion current velocity until the date of the last reading. In addition, the variations in cement consumption were not significant when results of speed and results of half-cell potential were observed.
\end{abstract}

Keywords: Corrosion, Passive film, Half-cell potential, Electrical resistivity, Durability. 
ESTEVES, I. C. A. et al., INFLUÊNCIA DO CONSUMO DE CIMENTO NA DOSAGEM DO CONCRETO SOBRE A FORMAÇÃO DA PELÍCULA PASSIVADORA DO AÇO. $3^{\circ}$ Simpósio Paranaense de Patologia das Construções (30 SPPC), artigo 3SPPC1013, pp. 143 - 155, 2018. DOI: $10.4322 / 2526-7248.013$

\section{Introdução}

A corrosão dos metais pode ser entendida como um processo natural em que, ao interagir com o meio, um material metálico tende a retornar ao seu estado de menor energia agregada. Na construção civil, é geradora de grandes prejuízos, exigindo altos investimentos para sua mitigação $[1,2]$.

Como difundido no meio técnico e científico, o aço no interior do concreto está protegido física e quimicamente. Fisicamente por estar separado do meio externo pelo cobrimento e quimicamente por estar envolto por uma película passivadora, cuja formação e estabilidade são atribuídas à elevada alcalinidade do próprio concreto. Pourbaix [3] descreve tal camada passivadora como uma película de óxidos invisível a olho nu e de alta aderência ao aço, gerada por uma reação eletroquímica rápida e extensa. Esta película garante ao aço taxas de corrosão desprezíveis, devido à sua alta resistência ôhmica - associada, ainda, ao bloqueio ao acesso de umidade, oxigênio e outros agentes agressivos à superfície da armadura - e à sua capacidade de inviabilizar a dissolução do ferro [4].

De acordo com Huet et al. [5], a formação da película ocorre em pH a partir de 10, valor inferior à real alcalinidade presente na solução dos poros do concreto (por volta de 12,5). Complementarmente, alguns autores [6,7], através de ensaios como espectroscopia de fotoelétrons excitados por Raios-X (XPS) e difração de Raios-X (DRX), conseguiram identificar a morfologia da película passivadora formada em barras de aço sob ambientes distintos, sendo composta por camadas mais finas, mais internas ou externas em relação à barra de aço. Assim, a película é composta por uma camada externa de hematita $\left(\alpha-\mathrm{Fe}_{2} \mathrm{O}_{3}\right)$ e maghemita $\left(\gamma-\mathrm{Fe}_{2} \mathrm{O}_{3}\right)$, uma camada intermediária de magnetita $\left(\mathrm{Fe}_{3} \mathrm{O}_{4}\right)$ e uma camada interna de wustita $(\mathrm{FeO})$. No concreto, de acordo com Poursaee [8], a espessura e consequente capacidade de proteção da película são potencializadas com o aumento do $\mathrm{pH}$ da solução intersticial conferida pelos álcalis resultantes da hidratação do cimento. Contudo, isto não altera a composição química da camada passivadora, como confirmado também por Ghods et al. [9], que, assim como Poursaee [8], observaram a melhora na integridade da camada passivadora com o aumento do $\mathrm{pH}$ de solução na qual se imergiu o aço.

Poursaee e Hanson [10] acompanharam de hora em hora a densidade da corrente de corrosão (icorr) e o potencial de corrosão (Ecorr) de barras de aço imersas em soluções alcalinas (similares à solução intersticial do concreto) e em argamassas. Os autores notaram diferenças na cinética de formação da película passivadora conforme o meio de imersão das barras de aço. A estabilização da icorr, ocorreu depois de 70 horas para barras imersas em solução, semelhante ao demonstrado por Sánchez et al. [11], enquanto para barras imersas em argamassas, a estabilização ocorreu somente depois de 160 horas (aproximadamente 7 dias). Para os autores, estes resultados são atribuídos à baixa alcalinidade da argamassa no início da hidratação e à maior mobilidade de íons na solução alcalina. Além disso, foi observada a diferença de evolução da permissividade relativa entre as formas de imersão, o que também reflete em disparidades relevantes na evolução do potencial de corrosão. A permissividade relativa está ligada à capacidade de um campo magnético ser perturbado por um meio dielétrico e, de acordo com Poursaee e Hanson [10], tal parâmetro depende da umidade, temperatura, polaridade do 
ESTEVES, I. C. A. et al., INFLUÊNCIA DO CONSUMO DE CIMENTO NA DOSAGEM DO CONCRETO SOBRE A FORMAÇÃO DA PELÍCULA PASSIVADORA DO AÇO. $3^{\circ}$ Simpósio Paranaense de Patologia das Construções ( $3^{\circ}$ SPPC), artigo 3SPPC1013, pp.

ambiente, mobilidade de íons e cargas elétricas no meio. No caso estudado, todos estes fatores são afetados pelas alterações inerentes à hidratação do cimento.

Macioski et al. [12] avaliaram a corrosão em barras de aço carbono, com e sem proteção superficial, imersas em soluções de diferentes $\mathrm{pH}$ e para duas idades (7 e 30 dias), com o auxílio do equipamento Potenciostato SP-200. Dentre as propriedades analisadas estão a velocidade de corrosão (Icorr) e o potencial de corrosão (Ecorr) - tendo como eletrodo de referência o cobre-sulfato de cobre. Os autores encontraram altos valores de taxa de corrosão para medidas realizadas em barras sem proteção aos 7 dias de idade - em torno de $0,9 \mu \mathrm{A} / \mathrm{cm}^{2}$. Com 30 dias de idade, foi observada uma diminuição da taxa de corrosão dessas barras, chegando a um valor em torno de $0,2 \mu \mathrm{A} / \mathrm{cm}^{2}$ - indicando uma baixa ou moderada velocidade de corrosão. Paralelamente, também para análise das barras de aço sem proteção superficial, o potencial de corrosão apresentou uma melhora na condição de probabilidade de corrosão quando comparadas as idades de 7 e 30 dias. Para 0 primeiro caso, a propriedade oscilou em torno de $-700 \mathrm{mV}$, enquanto que, para a segunda leitura, obtiveram valores variando de -6 a $-582 \mathrm{mV}$ - sem uma tendência definida para o período estudado.

Rocha [13] avaliou o potencial de corrosão de corpos de prova de concreto armado moldados com diferentes traços e concentração de íons cloretos. As proporções utilizadas pela autora resultaram em três consumos de cimento: $540 \mathrm{~kg} / \mathrm{m}^{3}, 421 \mathrm{~kg} / \mathrm{m}^{3}$ e $346 \mathrm{~kg} / \mathrm{m}^{3}$. Independente da proporção de cimento/agregados utilizada na dosagem do concreto, as leituras de potencial de corrosão oscilaram em torno de $450 \mathrm{mV}$ durante os primeiros 70 dias de idade das amostras, indicando uma atividade do processo de corrosão. Entretanto, estudos confirmam que tal alteração do potencial de corrosão ocorre durante a formação da película passivadora [12, 14, 15, 16]. Para Rocha [13], a consolidação da película se deu a partir do aumento do potencial de corrosão de todos os concretos em leituras realizadas com 98 dias, indicando um valor de $-200 \mathrm{mV}$ - baixa probabilidade de corrosão, conforme a ASTM C876:2015 [17].

$\mathrm{Na}$ bibliografia é possível notar grande quantidade de trabalhos que investigam a formação da camada passivadora de barras imersas em argamassas [10, 18] e em soluções sintéticas $[6,9,11,19,20,21]$ em comparação com estudos realizados com barras em amostras de concreto armado [13, 16], devido, principalmente, a maior precisão de análise dos materiais em contato com o aço. Apesar dos cuidados dos pesquisadores em tornar os meios de imersão mais similares possíveis às condições deste último meio de imersão, as diferenças na cinética da formação da película não podem ser ignoradas, como já apontado por Poursaee e Hanson [10]. Desta forma, este trabalho objetiva analisar a evolução do potencial de corrosão e da densidade de corrente de corrosão do aço inserido em corpos de prova de concreto armado moldados com diferentes consumos de cimento já apresentados na literatura.

\section{Programa Experimental}

Nesta seção são apresentados os materiais utilizados para moldagem dos corpos de prova de concreto, bem como os procedimentos utilizados para medição dos valores de potencial e velocidade de corrosão. 
ESTEVES, I. C. A. et al., INFLUÊNCIA DO CONSUMO DE CIMENTO NA DOSAGEM DO CONCRETO SOBRE A FORMAÇÃO DA PELÍCULA PASSIVADORA DO AÇO. $3^{\circ}$ Simpósio Paranaense de Patologia das Construções (30 SPPC), artigo 3SPPC1013, pp. 143 - 155, 2018. DOI: $10.4322 / 2526-7248.013$

\subsection{Materiais}

Para estudo das propriedades físico-químicas do concreto armado, foram moldados corpos de prova com três variações de traço para dosagem com aditivo superplastificante (ASP) com base de polímeros policarboxilatos. As amostras foram dosadas utilizando como aglomerante hidráulico o cimento Portland CP V-ARI, mantendo-se fixo o teor de argamassa em $52 \%$. O agregado graúdo utilizado possui diâmetro máximo de $12,5 \mathrm{~mm}$, correspondendo à brita zero. Foi considerada a umidade presente no agregado miúdo de 5,66\%. Esta umidade foi obtida a partir da separação de $100 \mathrm{~g}$ de amostra do material mantidos em estufa a $100^{\circ} \mathrm{C}$ até a constância de massa. A água, portanto, foi dosada considerando a umidade do agregado miúdo, tendo um abatimento de $60 \pm 10 \mathrm{~mm}$ para todos os concretos. $\mathrm{O}$ aço utilizado para a moldagem dos corpos de prova de concreto armado é o aço carbono CA-50, com diâmetro de $8 \mathrm{~mm}$. As informações referentes à nomenclatura dos concretos moldados, à proporção dos materiais secos, água e aditivo, bem como informação a respeito do abatimento do concreto fresco e da sua resistência à compressão média estão dispostos na Tabela 1.

Tabela 1: Composição e resistência dos concretos usados

\begin{tabular}{|c|c|c|c|c|c|c|c|}
\hline \multirow{2}{*}{ Amostra } & \multirow{2}{*}{$\begin{array}{l}\text { Consumo de } \\
\text { cimento } \\
\left(\mathrm{kg} / \mathrm{m}^{3}\right)\end{array}$} & \multicolumn{3}{|c|}{ Traço } & \multirow{2}{*}{$\begin{array}{c}\text { Relação } \\
\text { a/c }\end{array}$} & \multirow{2}{*}{$\begin{array}{c}\text { Teor ASP (\% } \\
\text { massa de } \\
\text { cimento) }\end{array}$} & \multirow{2}{*}{$\begin{array}{c}\mathrm{fcm} \\
(\mathrm{MPa})\end{array}$} \\
\hline & & Cimento & Areia & Brita & & & \\
\hline T245 & 245 & 1 & 3,94 & 4,56 & 0,59 & 0,09 & 33,0 \\
\hline T290 & 290 & 1 & 3,05 & 3,74 & 0,59 & 0,06 & 38,3 \\
\hline T320 & 320 & 1 & 2,60 & 3,33 & 0,59 & 0,02 & 39,7 \\
\hline
\end{tabular}

\subsection{Preparação das barras de aço}

Para moldagem dos corpos de prova de concreto armado, as barras de aço foram cortadas com $35 \mathrm{~cm}$ de comprimento. As barras ficaram imersas em solução de água e ácido clorídrico (5\%) durante 10 minutos para auxílio na remoção de eventuais produtos de corrosão previamente formados. Após este período, as barras foram lavadas em água corrente, secas e limpas com utilizando tecido umedecido com acetona. Por fim, lavou-se novamente as barras em água corrente; tal procedimento de limpeza foi adotado para garantir a remoção de vestígios da solução de $\mathrm{HCl}$ e inibir a ação deletéria de íons cloreto.

\subsection{Moldagem dos corpos de prova}

Os corpos de prova foram moldados em duas diferentes geometrias: cilíndrico ( $\varnothing$ $100 \times 200 \mathrm{~mm})$ e prismático $(250 \times 250 \times 70 \mathrm{~mm})$ Para ensaio de resistência à compressão axial, foram moldados três corpos de prova cilíndricos para cada traço, enquanto que, para a análise da formação da película passivadora do aço, foram moldados dois corpos de prova prismáticos de cada traço (contendo duas barras de aço em cada amostra, com um cobrimento de $30 \mathrm{~mm}$ ). Um esquema da geometria da amostra prismática é apresentado na Figura 1. Para adensamento do concreto, foi utilizada uma mesa vibratória, onde as fôrmas foram preenchidas com uma 
camada de material e adensadas durante 10 segundos. Após a desmoldagem, as regiões expostas das barras de aço foram cobertas com fita isolante e resina epóxi com a finalidade de proteger estas áreas da ocorrência de corrosão. Para a viabilização de contato elétrico com a barra e os equipamentos de leitura, foi instalado um fio de cobre sobre a barra e sob o material de proteção, mantendo uma ponta do fio voltada para o meio externo da proteção. Em seguida, os corpos de prova foram encaminhados à câmara úmida, com umidade relativa de $95 \%$ e temperatura em $23^{\circ} \mathrm{C} \pm 2^{\circ} \mathrm{C}$.
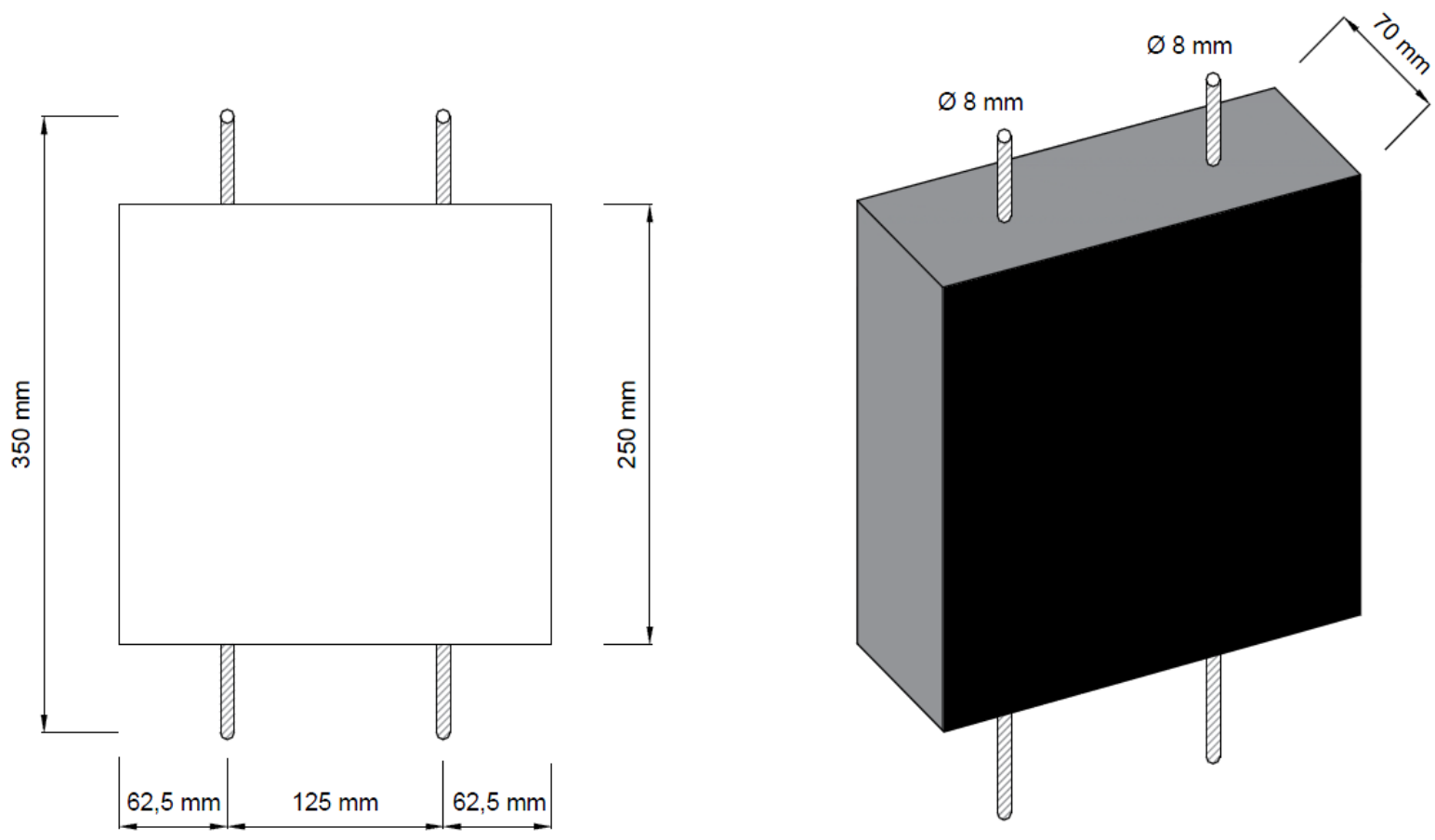

Figura 1: Corpo de prova prismático de concreto armado

\subsection{Ensaios realizados}

Foram efetuadas leituras de potencial de corrosão (Ecorr) e velocidade de corrosão (icorr) em oito idades diferentes (3, 10, 17, 24, 34, 38, 97 e 124 dias), utilizando como eletrodo de referência o Cu/CuSO4 através do equipamento GECOR-10, que realiza a leitura das propriedades simultaneamente. Além disso, foram realizadas leituras de resistividade do concreto em seis idades diferentes $(3,10,17,24,34$ e 38 dias) com uma sonda de Wenner (equipamento RESIPOD). É importante ressaltar que, entre os intervalos entre cada leitura dos ensaios, os corpos de prova prismáticos foram mantidos em câmara úmida, sendo retirados apenas nas datas de ensaio, quando foram umedecidos de forma a manter uma película de água visível sobre sua superfície durante todo o tempo em que se encontravam fora da câmara. Tal película de água era seca com tecido absorvente apenas para a realização dos ensaios, sendo formada novamente com o auxílio de um tecido úmido.

Para a caracterização do concreto utilizado, foi também determinada sua resistência à compressão no $35^{\circ}$ dia de idade. Reconhece-se aqui que a idade de realização deste ensaio foge do convencional de 28 dias, contudo, ao tratar-se de concretos produzidos com cimento de alta resistência inicial (CP V - ARI), observa-se variação 
ESTEVES, I. C. A. et al., INFLUÊNCIA DO CONSUMO DE CIMENTO NA DOSAGEM DO CONCRETO SOBRE A FORMAÇÃO DA PELÍCULA PASSIVADORA DO AÇO. $3^{\circ}$ Simpósio Paranaense de Patologia das Construções (30 SPPC), artigo 3SPPC1013, pp. 143 - 155, 2018. DOI: $10.4322 / 2526-7248.013$

pouco significativa de resistência em idades superiores ao $28^{\circ}$ dia, como encontrado em Medeiros-Junior et al. [22].

\subsection{Procedimentos de análise}

Para a interpretação das leituras de potencial de corrosão, foi utilizada a norma ASTM C 876:2015 [17] como referência, que estabelece faixas de valores para classificar a probabilidade de ocorrência da corrosão nas armaduras no interior do concreto. Na Erro! Fonte de referência não encontrada. são apresentados tais valores de referência.

Tabela 2 - Probabilidade de corrosão segundo a ASTM C 876:2015 [17]

\begin{tabular}{cc}
\hline Eletrodo de Cu/CuSO & Probabilidade de corrosão \\
\hline Mais eletropositivo que $-200 \mathrm{mV}$ & $>90 \%$ \\
Entre -200mV e -350mV & $50 \%$ \\
Mais eletronegativo que $-350 \mathrm{mV}$ & $<10 \%$ \\
\hline
\end{tabular}

Já para a análise da velocidade de corrosão, utilizou-se a classificação apontada por Hornbostel et al. [23], demonstrada na Tabela 3.

Tabela 3 - Condição de corrosão a partir da velocidade de corrosão (Fonte: adaptado de Hornbostel et al. [23])

\begin{tabular}{cc}
\hline Condição da velocidade de corrosão & icorr $\boldsymbol{\mu \mathbf { A } / \mathbf { c m } ^ { \mathbf { 2 } }}$ \\
\hline Passivação (Desconsiderável) & $<0,1$ \\
Baixa - Moderada & $0,1-0,5$ \\
Intermediária - Alta & $0,5-1$ \\
Muito alta & $>1$ \\
\hline
\end{tabular}

\section{Resultados e Discussões}

Nesta seção são apresentados os resultados referentes às leituras de potencial de corrosão, velocidade de corrosão e resistividade elétrica dos corpos de prova de concreto armado, bem como as análises acerca dessas informações.

\subsection{Potencial de corrosão}

A partir das leituras individuais de potencial de corrosão (Ecorr) em cada uma das duas barras de aço presentes nos corpos de prova de concreto armado, foi calculada a média dos valores obtidos para cada traço na idade de leitura. Essa média inclui quatro leituras em dois corpos de prova de um mesmo traço. Assim, para cada idade de ensaio, foram geradas três médias (referentes a cada traço de 
concreto), representadas na Fig. 2, onde também são apresentadas as faixas de probabilidade de corrosão (Tabela 2).

Para as armaduras dos corpos de prova de mesmo traço, observou-se uma sutil tendência de resultados até os 17 dias de idade, com pouca variação dos mesmos. No entanto, com o avanço da idade do concreto, nota-se uma perturbação nos valores de potencial de corrosão de todas as amostras, variando de $-184,25 \mathrm{mV}$ a $475,85 \mathrm{mV}$ na idade de 34 dias. Essa oscilação em idades iniciais do concreto armado também foi registrada em outros estudos [12, 14, 16], sendo apontada como reflexo da atividade de corrosão durante a formação da película passivadora. Comparativamente, Gurdián et al. [24] encontraram uma grande oscilação de resultados de potencial de corrosão após 24 dias de idade para concretos moldados com cimento Portland sem adição. Rocha [13] só obteve resultados positivos para formação da película passivadora (potencial de corrosão maior que -200 mV para $\mathrm{Cu} / \mathrm{CuSO} 4$ como eletrodo de referência, segundo a ASTM C8786:2015 [17]) após 98 dias de idade do concreto. A partir da leitura com 97 dias, no entanto, todas as amostras deste trabalho apresentaram alta probabilidade de corrosão, permanecendo na faixa de alta probabilidade de corrosão até a leitura de 138 dias de idade. Com relação ao consumo de cimento, este fator mostrou-se pouco significativo a partir da análise de variância feita com confiabilidade de 95\%.

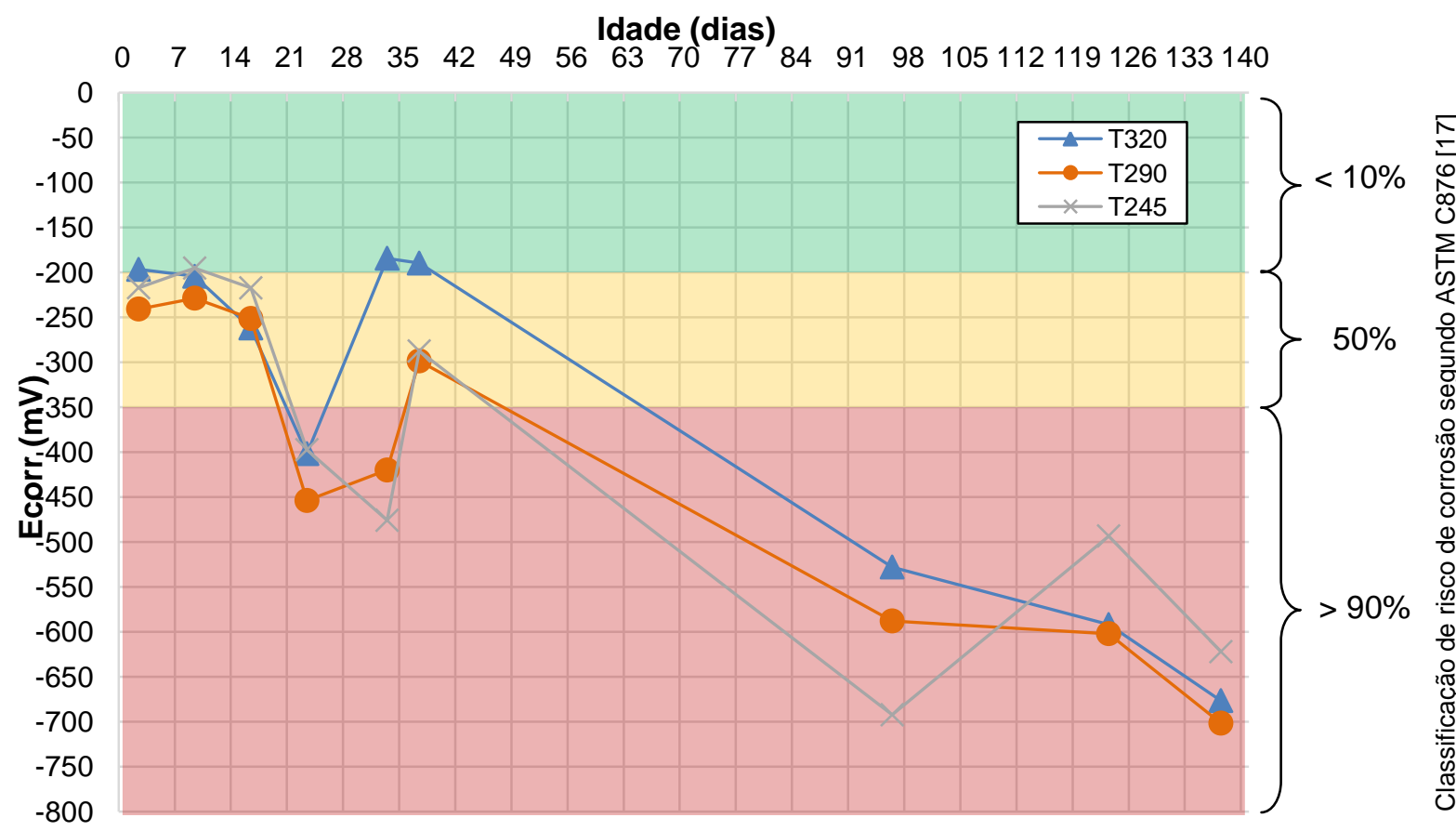

Figura 2: Média das leituras de potencial de corrosão para cada traço de concreto em diferentes idades

De acordo com González et al. [25], os resultados de potencial de corrosão podem variar durante dias até que alcancem uma estabilidade, o que pode justificar os resultados encontrados. Segundo os autores, as leituras da propriedade não devem ser interpretadas de maneira isolada, sendo necessários resultados de outros ensaios que complementem a análise, como os de velocidade de corrosão e resistividade elétrica superficial. 
De maneira similar, ao acompanhar a evolução do potencial de corrosão de corpos de prova produzidos com concretos contendo diferentes consumos de cimento, Medeiros et al. [16] não observaram efeito dos diferentes consumos de cimento do concreto sobre os resultados. Contudo, é essencial destacar aqui, que, no estudo de Medeiros et al. [16], variou-se a relação a/c para os diferentes traços, mantendo-se apenas a consistência do concreto ensaiado. O mesmo não ocorre para este trabalho, apesar de também ser observada aqui pouca significância da variação do consumo de cimento para os resultados de potencial de corrosão, até as idades medidas.

\subsection{Velocidade de corrosão}

Assim como nas leituras de potencial de corrosão, foram calculadas as médias dos resultados obtidos para a velocidade de corrosão (icorr) do aço para cada traço de concreto em estudo. Essas informações são apresentadas na Fig. 3, assim como as condições de corrosão, expostos na Tabela 3.

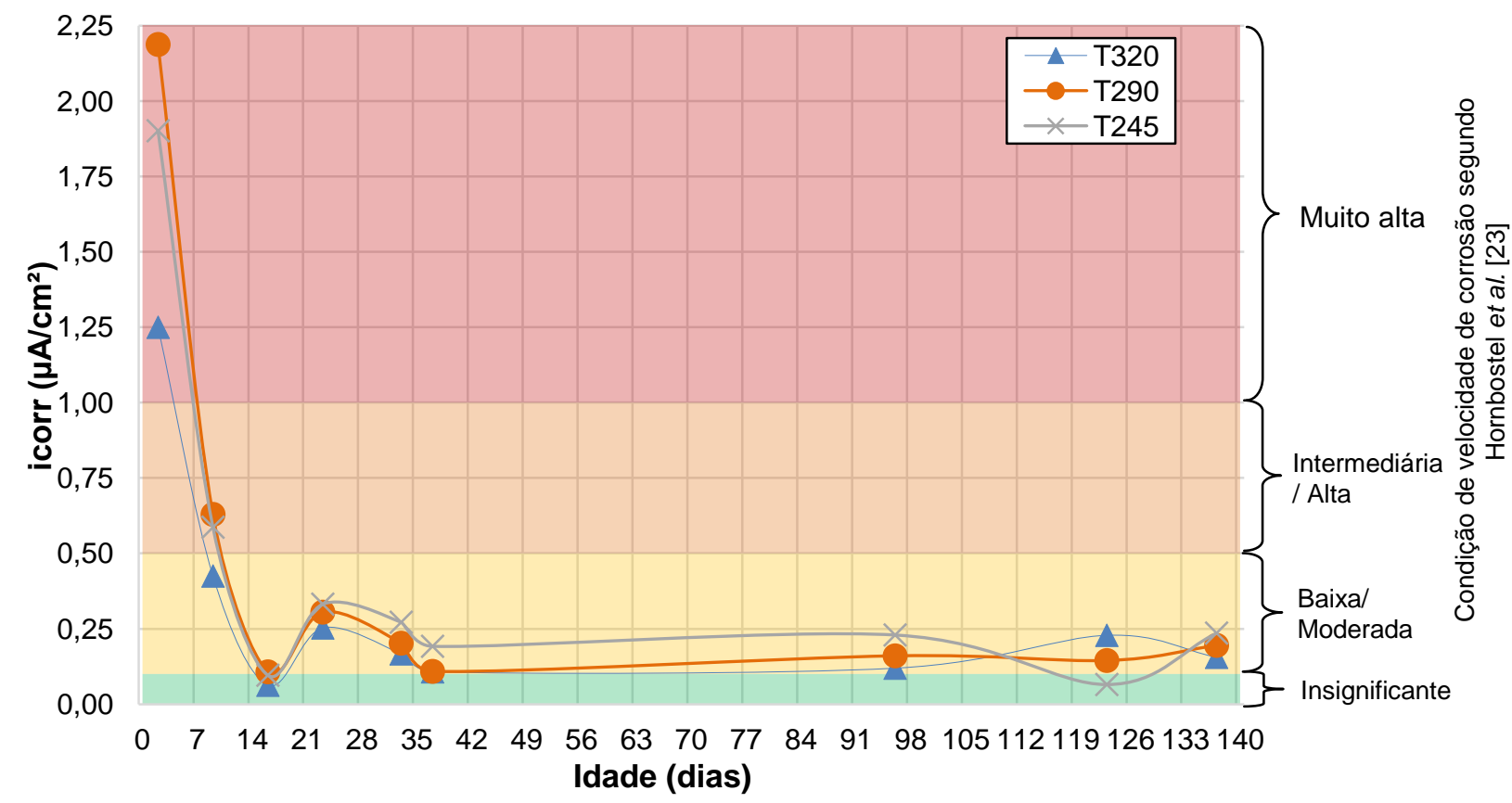

Figura 3: Média das leituras de velocidade de corrosão para cada traço de concreto em diferentes idades

Paralelamente ao potencial de corrosão, a velocidade de corrosão das amostras também apresentou uma perturbação nos resultados após a idade de 17 dias. Até o $3^{\circ}$ dia de idade, todos os corpos de prova apresentaram alta velocidade de corrosão (acima de 1,0 $\mu \mathrm{A} / \mathrm{cm}^{2}$ ). No entanto, a partir do $10^{\circ}$ dia de idade, as barras de aço apresentaram-se na zona de baixa a moderada velocidade de corrosão - entre 0,1 e $1,0 \mu \mathrm{A} / \mathrm{cm}^{2}$ - com algumas chegando a entrar na condição de passivação (inferior a $0,1 \mu \mathrm{A} / \mathrm{cm}^{2}$ ). A partir de 34 dias de idade, as leituras de velocidade de corrosão seguintes para os três concretos não apresentaram variação significativa até a leitura com idade de 138 dias (confirmado através de análise de variância com nível de confiabilidade de $95 \%$ ). 
ESTEVES, I. C. A. et al., INFLUÊNCIA DO CONSUMO DE CIMENTO NA DOSAGEM DO CONCRETO SOBRE A FORMAÇÃO DA

Os resultados apresentados não permitem afirmar com certeza a formação completa de película passivadora até a data medida, uma vez que se apresentaram constantes e superiores a $0,1 \mu \mathrm{A} / \mathrm{cm}^{2}$ até o último dia medido. Assim, analisando o efeito do teor de cimento sobre a velocidade de corrosão, é possível concluir que este se mostrou irrelevante (análise de variância com confiabilidade de 95\%). No entanto, houve maior velocidade de corrosão nos concretos T290 e T245 até a leitura com 97 dias de idade (sendo essa diferença mais significativa aos 3 dias de idade).

\subsection{Resistividade elétrica superficial}

Por ser um parâmetro relativo ao concreto, a resistividade elétrica (RES) é medida apenas em duas amostras (prismas de concreto) e não em quatro amostras (barras de aço) como nos parâmetros anteriores. A Fig. 4 apresenta os valores medidos, para cada idade, para os prismas produzidos com os consumos baixo, intermediário e alto de cimento. Como a diferença de resistividade entre as duas últimas leituras não é estatisticamente significativa através de comparação múltipla de médias e a tendência para a resistividade do concreto é a estabilização, não foram feitas mais leituras a partir da sexta idade.

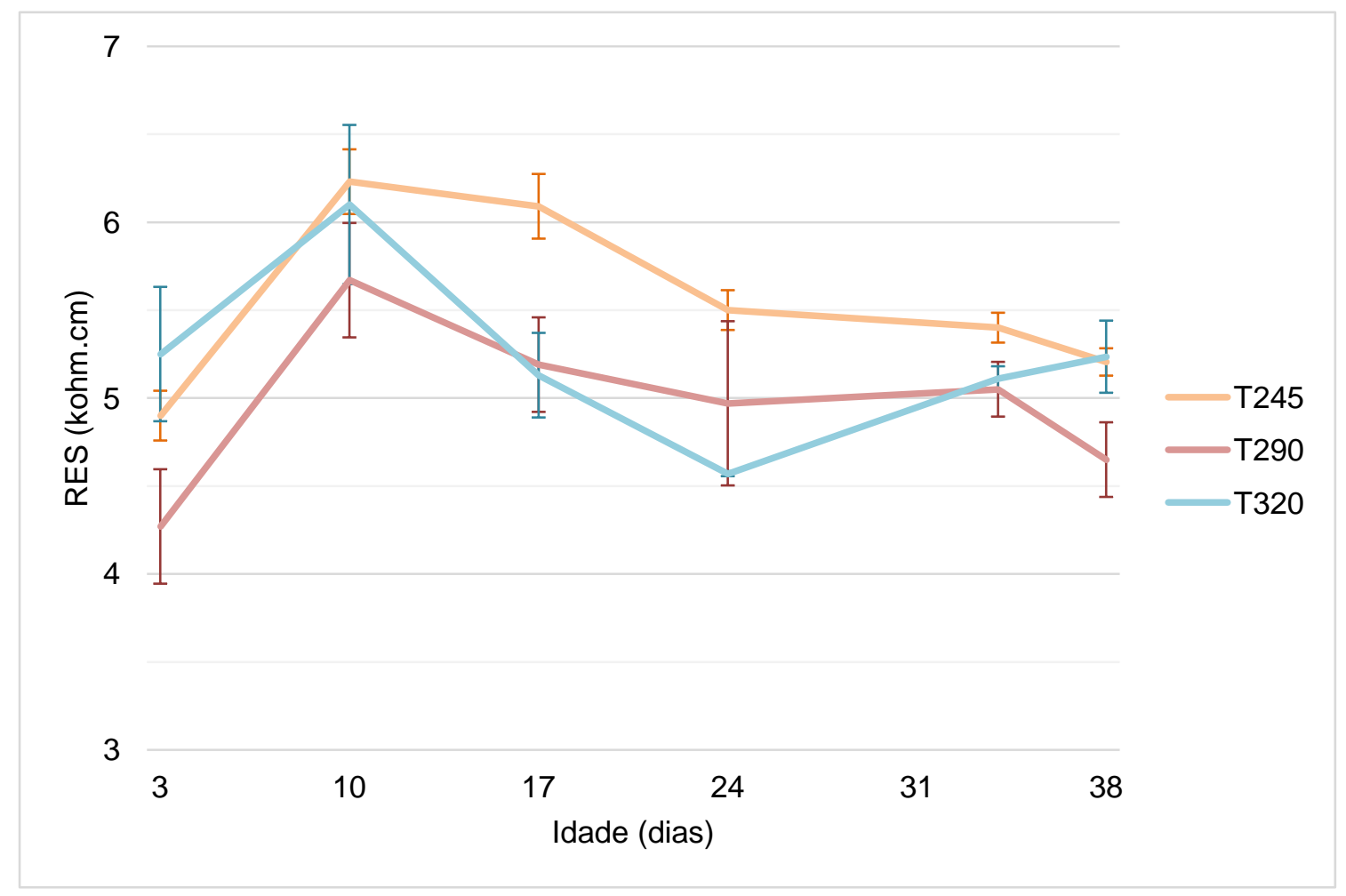

Figura 4: Resistividade do concreto para T320, T290 e T245

A partir das medidas de RES, é possível observar que não há padrão quando busca-se analisar os efeitos do teor de cimento e até mesmo da idade sobre os resultados. Como pode-se observar na Fig. 4, a resistividade medida não apresenta crescimento contínuo, como esperado tendo em vista a continuidade da hidratação do cimento ao longo do tempo. Quando comparados estatisticamente os efeitos da idade de medição, por meio de teste de hipóteses por análise de variância, constatou-se, com mais de $95 \%$ de certeza que a variação no consumo de cimento 
ESTEVES, I. C. A. et al., INFLUÊNCIA DO CONSUMO DE CIMENTO NA DOSAGEM DO CONCRETO SOBRE A FORMAÇÃO DA PELÍCULA PASSIVADORA DO AÇO. $3^{\circ}$ Simpósio Paranaense de Patologia das Construções (30 SPPC), artigo 3SPPC1013, pp. 143 - 155, 2018. DOI: $10.4322 / 2526-7248.013$

influencia na resistividade do concreto. Tratando-se da idade do concreto, notou-se, por meio de comparação múltipla de médias que para o traço T245 as diferenças medidas registradas a partir do $24^{\circ}$ dia não são significativas, para o traço T290 não há diferença significativa a partir do $17^{\circ}$ dia e para o traço 7320 as diferenças entre leituras deixam de ser significativas a partir do dia 34.

Para concretos de consumo de cimento $420 \mathrm{~kg} / \mathrm{m}^{3}$, mais elevado que os três traços aqui apresentados, e relação a/c 0,60, bem próxima do 0,59 utilizado para a produção de corpos de prova deste trabalho, Medeiros-Junior et al. [22] encontraram resistividades levemente inferiores às dos três concretos aqui apresentados (abaixo de 5 kohm.com aos 91 dias e abaixo de 3 kohm.cm aos 28 dias). O trabalho citado apresenta também tendência de crescimento da RES ao longo do tempo, o que não é confirmado em nenhum dos traços aqui apresentados, já que há uma queda de resistividade significativa para os três quando comparados os resultados do $10^{\circ}$ e do $38^{\circ}$ dia.

Quando analisados os valores aqui obtidos com base nos critérios da recomendação europeia RILEM 154 [26], pode-se afirmar que os riscos de corrosão são elevados quando perdida a passividade da película passivadora, uma vez que a baixa resistividade do eletrólito formado pela solução intersticial do concreto pode favorecer o transporte de íons em uma pilha de corrosão. Tais valores baixos de RES são comuns para concretos com baixos teores de adições cimentícias ou pozolânicas como apontado por Medeiros-Junior et al [22]. A baixa resistividade do concreto pode também ser uma das razões para tanto a velocidade de corrente quanto o potencial de corrosão não terem apresentado valores estabilizados que indicassem a inexistência de corrosão até o final das leituras aqui realizadas.

\section{Considerações Finais}

Ao analisar leituras de ensaios de pontencial de corrosão, velocidade de corrosão e resistividade elétrica do concreto em corpos de prova prismáticos de concreto com três concentrações de cimento diferentes contendo barras de aço CA-50, este trabalho, permite considerar que:

- Apesar da queda contínua da velocidade de corrosão nas barras de aço dos corpos de prova para os três diferentes traços, até 140 dias ainda não é possível afirmar a consolidação de camada passivadora para as armaduras imersas em concreto.

- Após seguidas quedas na eletronegatividade do potencial de corrosão para níveis de baixa probabilidade de ocorrência de corrosão das barras de aço estudadas, perturbações nesta tendência e a elevação a níveis de alta probabilidade de corrosão puderam ser notadas a partir do 24을 dia reafirmando a impossibilidade de confirmar a existência de camada passivadora até as últimas datas de leitura quando associados os resultados de potencial e velocidade de corrosão.

- Os concretos produzidos apresentam baixa resistividade, o que pode ser um dos fatores a contribuir na inconsistência dos parâmetros que podem indicar a formação de película passivadora. 
- A variação no consumo de cimento mostrou-se pouco significativa para o potencial de corrosão e para a velocidade de corrosão. Contudo, é importante destacar que tais variações são relativamente pequenas e que os traços aqui podem ser considerados de pobres a intermediários em teor de cimento. Recomenda-se, portanto, que novos estudos sejam feitos incluindo traços ricos em cimento.

\section{Referências}

[1] Helene, P. R. L. (1993) Contribuição ao estudo de corrosão em armaduras de concreto armado. Tese (Livre Docência), Universidade de São Paulo - USP, São Paulo, Brasil.

[2] Cascudo, O. (1997) O controle da corrosão de armaduras em concreto inspeção e técnicas eletroquímicas. Pini, São Paulo, Brasil.

[3] Pourbaix, M. (1987) Lecciones de corrosión electroquímica. 3a ed. Cebelcor, Bruxelas, Bélgica.

[4] Figueiredo, E. P.; Meira, G. R. (2011) Corrosão das Armaduras das Estruturas de Concreto. In: ISAIA, Geraldo Cechella. Concreto: Ciência e Tecnologia. Ibracon: São Paulo, Brasil, 903-932.

[5] Huet, B.; L'Hostis, V.; Miserque, F.; Idrissi, H. (2005) Electrochemical behavior of mild steel in concrete: Influence of $\mathrm{pH}$ and carbonate content of concrete pore solution. Electrochimica Acta, 51, 1: 172-180.

[6] Al, Z.; Sun, W.; Jiang, J.; Song, D.; Ma, H.; Zhang, J.; Wang, D. (2016) Passivation Characteristics of Alloy Corrosion-Resistant Steel Cr10Mo1 in Simulating Concrete Pore Solutions: Combination Effects of $\mathrm{pH}$ and Chloride. Materials, 9, 749.

[7] Pan, T.; Lu, Y. (2011) Quantum-Chemistry Based Studying of Rebar Passivation in Alkaline Concrete Environment. International Journal of Electrochemical Science, 6: 4967-4983.

[8] Poursaee, A. (2010) Corrosion of steel bars in saturated $\mathrm{Ca}(\mathrm{OH})_{2}$ and concrete pore solution. Concrete research letters, 1, 3: 90-97.

[9] Ghods, P. et al. (2009) The effect of concrete pore solution composition on the quality of passive oxide films on black steel reinforcement. Cement and Concrete Composites, 31,1: 2-11.

[10] Poursaee, A.; Hansson, C. M. (2007) Reinforcing steel passivation in mortar and pore solution. Cement and Concrete Research, 37, 7: 1127-1133.

[11] Sánchez, M. et al. (2007) Electrochemical impedance spectroscopy for studying passive layers on steel rebars immersed in alkaline solutions simulating concrete pores. Electrochimica Acta, 52, 27: 7634-7641.

[12] Macioski, G.; Souza, D. J.; Brandão, A. P. C.; Medeiros, M. H. F. (2016) Análise da corrosão de barras de aço em função da variação do $\mathrm{pH}$ do meio. Revista ALCONPAT, 6, 3: 223-234.

[13] Rocha, F. C. (2012) Leituras de potencial de corrosão em estruturas de concreto armado: influência da relação água/cimento, da temperatura, da 
ESTEVES, I. C. A. et al., INFLUÊNCIA DO CONSUMO DE CIMENTO NA DOSAGEM DO CONCRETO SOBRE A FORMAÇÃO DA PELÍCULA PASSIVADORA DO AÇO. $3^{\circ}$ Simpósio Paranaense de Patologia das Construções (30 SPPC), artigo 3SPPC1013, pp. 143 - 155, 2018. DOI: $10.4322 / 2526-7248.013$

contaminação por cloretos, da espessura de cobrimento e do teor de umidade do concreto. Dissertação (Mestrado em Engenharia de Construção Civil), Universidade Federal do Paraná - UFPR, Curitiba, Brasil.

[14] Araújo, A. (2004) Estudo para o estabelecimento de metodologia de avaliação de vernizes na proteção ao concreto armado contra a penetração de agentes agressivos. Dissertação (Mestrado em Engenharia Civil) - Instituto de Pesquisas Tecnológicas do Estado de São Paulo (IPT), São Paulo.

[15] Medeiros, M. H. F., Pereira, E., Quarcioni, V. A., Helene, P. R. L. (2016) Surface treatment systems for concrete in marine environment: Effect of concrete cover thickness. REM - International Engineering Journal, 69, 3: 287-292.

[16] Medeiros, M. H. F.; Rocha, F. C.; Medeiros-Junior, R. A.; Helene, P. (2017) Potencial de corrosão: influência da umidade, relação água/cimento, teor de cloretos e cobrimento. Revista Ibracon de Estruturas e Materiais, 10, 4: 864 885.

[17] ASTM C-876 (2015) Standard Test Method for Corrosion Potentials of Uncoated Reinforcing Steel in Concrete. American Society for Testing and Materials ASTM, West Conshohocken, Estados Unidos.

[18] Andrade, C. Keddamb M.; Nóvoa X. R.; Pérez, M. C.; Rangel C. M.; Takenouti, H. (2001) Electrochemical behaviour of steel rebars in concrete: influence of environmental factors and cement chemistry. Electrochimica Acta, 46, 24: 3905-3912.

[19] Sánchez, M. et al. (2006) Anodic growth of passive layers on steel rebars in an alkaline medium simulating the concrete pores. Electrochimica acta, 52, 1: 4753.

[20] Valcarce, M. B.; Vázquez, M. (2008) Carbon steel passivity examined in alkaline solutions: the effect of chloride and nitrite ions. Electrochimica Acta, 53, 15: 5007-5015.

[21] Gunay, H. et al. (2013) Characterization of atomic structure of oxide films on carbon steel in simulated concrete pore solutions using EELS. Applied Surface Science, 274: 195-202.

[22] Medeiros-Junior, R. A.; Lima, M. G.; Medeiros, M. H. F.; Real, L. V. (2014) Investigação da resistência à compressão e da resistividade elétrica de concretos com diferentes tipos de cimento. Revista de la Asociación Latinoamericana de Control de Calidad, Patología y Recuperación de la Construcción, 4, 2: 116-132.

[23] Hornbostel, K.; Larsen, C. K.; Geiker, M. R. Relationship between concrete resistivity and corrosion rate - A literature review. Cement and Concrete Composites, 39: 60-72.

[24] Gurdián, H.; García-Alcocel, E.; Baeza-Brotons, F.; Garcés, P.; Zornoza, E. (2014) Corrosion behavior of steel reinforcement in concrete with recycled aggregates, fly ash and spent cracking catalyst. Materials, 7: 3176-3197. 
ESTEVES, I. C. A. et al., INFLUÊNCIA DO CONSUMO DE CIMENTO NA DOSAGEM DO CONCRETO SOBRE A FORMAÇÃO DA PELÍCULA PASSIVADORA DO AÇO. $3^{\circ}$ Simpósio Paranaense de Patologia das Construções (30 SPPC), artigo 3SPPC1013, pp. 143 - 155, 2018. DOI: $10.4322 / 2526-7248.013$

[25] González, J. A.; Miranda, J. M.; Feliu, S. Considerations on reproducibility of potential and corrosion rate measurements in reinforced concrete. Corrosion Science, 46: 2467-2485.

[26] TC 154-EMC (2000) Eletrochemical techniques for measuring metallic corrosion. Réunion Internationale des Laboratoires et Experts des Matériaux RILEM, Paris, França. 